\title{
Discerned Fragments in Feces Indicates Diet Overlap
}

\section{R. M. HANSEN, D. G. PEDEN, AND R. W. RICE}

Highlight: $A$ mean dissimilarity index was used to measure the degree of dietary overlap of appropriately paired diet and fecal samples of cows, bison, and sheep. When botanical composition is determined by the microscope technique for plant fragments identified in the feces of different kinds of herbivores (cattle, sheep, and bison), the estimated degree of dietary overlap is approximately the same as if diet samples had been used to estimate dietary overlap.

The occurrence of recognizable plant fragments in the feces of livestock and wild herbivores has been used in the scientific literature (Dusi, 1949; Storr, 1968) for the determination of botanical composition of diets. Normally the relative discernability of plant fragments in the feces decreases as the digestibility of plant species increases (Casebeer and Koss, 1970; Free et al., 1970; Grenet, 1966; Regal, 1960; Stewart, 1967). The difference in thickness of the plant cell walls before and after digestion in steers can be used to estimate the plant's digestibility (Regal, 1960).

Use of a polarizing microscope and new slide preparation techniques permits recognition of most epidermal fragments (Storr, 1961 and 1968; Williams, 1969). The purpose of this paper is to examine the potential use of identifying plant fragments in fecal samples to quantitatively describe dietary overlap. The purpose of this approach is the desire to overcome the difficultics both in observing feeding behavior and in the fistulation of herbivores in order to estimate dietary overlap. The results obtained from fecal samples are compared to those obtained from esophageal samples by use of an index of dissimilarity.

\section{Methods and Materials}

Dietary overlap was evaluated for dif-

The authors are professor and research assistant, Department of Range Science, Colorado State University, Fort Collins; and professor, Animal Science Department, University of Wyoming, Laramie.

This study was supported in part by Colorado State University Agricultural Experiment Station and National Science Foundation grants GB-7824 and GB-13096.

Man uscript received November 26, 1971. ferent herbivores, sites, stocking levels, and seasons. Control samples (esophageal) were collected from three bison and two cows on light and heavily stocked pastures in northcentral Colorado during May of 1970. Two independent sets of mean botanical compositions were obtained for each sample. For each sample an index was derived in order to observe how much dissimilarity could be expected from laboratory error alone.

Corresponding diet and fecal samples were obtained from esophageally fistulated cattle and bison from two blue grama (Bouteloua gracilis) dominated ranges. One site was in northeastern Colorado (N.E.) and the other was in northcentral Colorado (N.C.).

The sheep feces were collected from metabolism cages. The sheep were fed the four composited esophageal fistula samples each taken from steers grazing during each of the four seasons on a pasture lightly grazed by cattle at the northeastern Colorado site (Wallace and Denham, 1970). In the data analysis it was assumed that the diets of the N.E. steers and the sheep were identical. The cattle and bison samples from the northcentral Colorado site were each from spring and autumn and each from pastures grazed by cattle at light, moderate, and heavy stocking rates.

Dissimilarity indices were developed for each individual animal's diet-fecal pair. For each species-site combination, mean index (I) values were obtained. These were then compared to the control by paired $t$ tests in order to see whether the dissimilarity between dict and fecal samples could be explained in terms of sampling error. On the basis of these comparisons, dissimilarity indices were derived for different herbivores, different sites and different seasons, and crosscomparisons. 
Dissimilarity index used in this study is a modification of Ivlev's standard deviation of food densities (Watt, 1968).

Denote the dissimilarity index as I. Let the subscripts $e$ and $f$ designate the nature of the compared diets where $e$ indicates ingesta and $f$ indicates feces. Thus $\mathrm{I}_{\mathrm{ee}}, \mathrm{I}_{\mathrm{ef}}$, and $I_{f f}$ imply comparisons of two ingesta samples, one ingesta and one fecal sample, and two fecal samples respectively. Then

$$
I_{e e}=\sqrt{\sum_{i=1}^{N} \frac{\left(d_{i 1}-d_{i 2}\right)^{2}}{N-1}}
$$

where $d_{i 1}$ and $d_{i 2}$ are the relative densities of recognized fragments of the ith plant in ingesta samples 1 and 2 respectively. $\mathrm{N}$ denotes the total number of plants encountered in both samples. Similarily

$$
I_{c f}=\sqrt{\sum_{i=1}^{N} \frac{\left(d_{i 1}-d_{i 2}\right)^{2}}{N-1}}
$$

is the dissimilarity index when one ingesta and one fecal sample are being comparcd and

$$
I_{f f}=\sqrt{\sum_{i=1}^{N} \frac{\left(d_{i 1}-d_{i 2}\right)^{2}}{N-1}}
$$

is the dissimilarity index when two fecal samples are being compared for overlap.

The index, I, will approach zero as the number of plant components in sample 1 become more similar to their counterparts in sample 2. Conversely, the index, I, will increase in value and thus denote greater dissimilarity when each of the number of plant components in sample 1 are less similar to their counterparts in sample 2.

Use of the index, I, necessitates certain assumptions when applied to fecal samples. First, the digestion of a specific plant leafy material in one herbivore is a linear function of that in another herbivore. This has been suggested by Peden (1972). Secondly, the subdividing of large particles from both esophageal and fecal samples by grinding results in plant particles that represent a similar weight value and thereby removes the effect of differential leaf fragmentation. This last assumption has been suggested by Cavender and Hansen (1970).

The microscope technique used to quantify the discerned plant fragments in the samples was described by Sparks and Malechek (1968). The relative percent density (RD) of identified fragments of plants in each of the diet and fecal samples was estimated by observing 20 systematically located fields on each of 20 slides with a microscope at about 100 power magnification. The occurrence of each recognized species of plant in each field was recorded. Average percent fre- quency was computed for all plant species identified in the samples. The RD, calculated as the number of recognized fragments of a species and expressed as a percentage of the total number of fragments of all species (Curtis and McIntosh, 1950), was calculated for each species of plant.

The identification procedures used in this study were described by Baumgartner and Martin (1939) and by Dusi (1949).

\section{Results and Discussion}

There are no statistically significant differences between the control and any one diet-fecal comparison (Table 1). Therefore, we can assume that dissimnot a technique error. However, the diet-fecal comparisons showed that the northcentral Colorado cattle were significantly different from the other three diet-fecal mean indexes.

Similar $t$ tests were used to compare the dissimilarity between sites, season, and grazing intensity. In these comparisons there were no significant differences.

There was a significant difference within cattle from northcentral Colorado even though there was no significant difference between the comparable diets of cattle and bison at this site.

In this study, the "best" fistula-fecal pairs were those of the sheep, because they were fed four whole samples. The samples were studied for plant species composition by taking from each 20 or more sub-samples for determining the percent relative densities (RD's) of recognized fragments. Since all the feces of the sheep for each season were pooled and then subsampled for RD's of recognized fragments the fistula-fecal pairs of sheep seem to have been "near-perfectly" matched. By pooling the fistula and fecal subsamples of the whole samples, a homogeneous mixture was obtained so that the variance between microscope slides was not influenced by the sequence of ingestion or the sequence of digestion, and there was no way in which the solid excreta could not have been the residue ilarity in the diet-fecal comparison was

of the known diets. The mean $\mathrm{I}_{\mathrm{ef}}$ index within sheep was $2.18 \pm .56$ and within the steers the index was $2.73 \pm .83$ and although the difference is not significant we believe the higher index for steers resulted because the steer fistula samples did not as perfectly match the "true diets" of the steers as well as the steer fecal samples did represent the "true diets." Even though the rumen contents are being well mixed during digestion it is common knowledge that the solid excreta defecated within any given hour or two roughly represents a sequence of ingestion.

The assumption that there is differential digestibility of fragments between different plants is valid, which results in lower relative discernability of fragments in the feces than in the forage, more so for highly digestible plants than for others. However, discernible fragments in feces, apart from being fragmented and stained differently from comparable fragments in fistula material, have the same epidermal cell patterns. The observed differences between easily discernible (resistant plants) plant species and those that are not (fragile plants) appear to be associated with the distribution of cutin (Storr, 1961). The cuticle extends down between cells and completely surrounds them for the epidermal cells of "resistant plants," but only the outer wall of the epidermis is covered with cutin of "fragile plants". Thus, the observed RD's of fragments in feces owes its discernibility to the degree to which cells are encased in cutin and lignin; both generally appear to be undigested.

The process whereby leaf fragments are broken down into fine particles facilitates digestion because this renders solublc plant protoplasm more available through leaching into the rumen fluids. That there is a gradual erosion of cell walls of resistant plants in rumen digestion has been shown by Regal (1960). The problem of dissolving the resistant leaf fragments that have already leached their soluble products is accom-

Table 1. Comparison of mean dissimilarity index values, I, with control.

\begin{tabular}{lccccc}
\hline \hline $\begin{array}{l}\text { Sample } \\
\text { types }\end{array}$ & $\begin{array}{c}\text { Mean (\%) } \\
\text { index (I) }\end{array}$ & $\begin{array}{c} \pm \text { S.D. } \\
\text { of (I) }\end{array}$ & $\begin{array}{c}\text { No. of } \\
\text { data sets }\end{array}$ & $\begin{array}{c}\text { t for test } \\
\text { with control }\end{array}$ & $\begin{array}{c}\text { Significant difference } \\
\text { from control }\end{array}$ \\
\hline $\begin{array}{l}\text { Control (N.E.) } \\
\text { Cattle }\end{array}$ & 5.58 & 2.75 & 10 & - & - \\
N.E. & 2.73 & .83 & 5 & 0.92 & No \\
N.C. & 8.50 & 0.93 & 5 & 0.96 & No \\
Sheep (N.E.) & 2.18 & .56 & 5 & 1.16 & No \\
Bison (N.C.) & 2.67 & 1.76 & 5 & 0.86 & No \\
\hline
\end{tabular}

${ }_{1}^{1}$ Diets and feces from northeastern Colorado (N.E.) and northcentral Colorado (N.C.).

2 Degrees of freedom $=13$. 
plished with enzymes found in the rumen fluids. However, if the observed differences in discernibility of plant fragments before and after digestion are similar among different species of herbivores, it seems logical that diet overlap can be measured even when small, significant differences in mean ability to digest exist among the herbivores.

There are three potential explanations for a higher mean index for cattle at northcentral Colorado in contrast to other similar paired samples used in this study. The fragments of blue grama and other plants known to decompose slowly were relatively more abundant in the N.C. cattle feces than in the N.C. fistula samples. One explanation is that the N.C. cattle fistula samples did not closely represent the cattle diets. The second is that cattle can digest the forage much more completely than can bison. Both seem to be unlikely since the diets were collected twice a day and composited in similar ways to that of other samples, and cattle do not digest forage from the area any better than do bison (Peden, 1972). The third, and most likely, explanation for the large differential in RD's of fistula and fecal samples is that the feces was collected in fecal bags and there was a significant amount of microbial decomposition that occurred after the solid excreta had been voided. The fragments of plants suspected to be "fragile" were relatively less discernible in the cattle feces than we would expect if the erosion of cell walls by digestion had been normal. Total collections in fecal bags and storage of feces in plastic bags awaiting processing probably permitted enzymatic activity to continue after "cow" digestion of fragments had ended. To insure that the differences in fecal overlap indexes do represent diet overlap, the excreta collecting techniques must be the same for each species of herbivore.

We believe that a microscopic analysis of feces can be used to estimate the approximate amount of diet overlap between different herbivores as long as comparable samples are obtained by a standard technique. Correction factors are not required to account for either differences between the digestibility of different plants or for differences between species of herbivores in the extent to which they digest any single plant. Even though the establishment of such regressions might be desirable and scientifically valuable, a great deal of practical use can be obtained from fecal indexes.

\section{Literature Cited} Plant histology as an aid in squirrel foodhabits studies. J. Wildl. Manage. 3:266-268.

Casebeer, R. L., and G. G. Koss. 1970. Food habits of wildebeest, zebra, hartebeest, and cattle in Kenya Masailand. E. Africa Wildl. J. $8: 25-36$. microscope method used for herbivore diet estimates and botanical analysis of litter and mulch at the Pawnee Site. U. S. Int. Biol. Grasslands Biome Tech. Rep. No. 18, 10 p. Nat. Res. Ecol. Lab., Ft. Collins.

Curtis, J. T., and R. P. McIntosh. 1950. The interrelations of certain analytic and synthetic phytosociological characters. Ecology 31:434-455.

Dusi, J. L. 1949. Methods for the determination of food habits by plant and microtechniques and histology and their application to cottontail rabbit food habits. J. Wildl. Manage. 13:295-298.

Free, J. C., R. M. Hansen and P. L. Sims. 1970. Estimating the dryweights of foodplants in feces of herbivores. J. Range Manage. 23:300-302.

Grenet, E. 1966. Less particules vegetales des feces de mouton. Ann. Zootech. 15:303-312.

Peden, D. G. 1972. Range Science Department.
Baumgartner, L. L., and A. C. Martin. 1939.

Cavender, B. R., and R. M. Hansen. 1970. The
Ph.D. Dissertation, Colorado State University.

Regal, V. 1960. The evaluation of the quality of pasture grasses by the microscopic method. Pro. of the VIII Int. Grasslands Cong. p. 522-524.

Sparks, D. R., and J. C. Malechek. 1967. Estimating percentage dryweight in diets. $J$. Range Manage. 21:203-208.

Stewart, D. R. M. 1967. Analysis of plant epidermis in faeces: a technique for studying the food preferences of grazing herbivores. J. Applied Ecol. 4:83-111.

Storr, G. M. 1961. Microscopic analysis of faeces, a technique for ascertaining the diet of herbivorous mammals. Australian J. Biol. Sci. 14:157-164.

Storr, G. M. 1968. Diet of kangaroos (Megaleia rufa and Macropus robustus) and Merino sheep near Port Hedland, Western Australia. The Royal Soc. Western Australia. $51: 25-32$.

Wallace, J. D., and A. H. Denham. 1970. Digestion of range forage by sheep collected by esophageal fistulated cattle. J. Anim. Sci. 30:605-608.

Watt, K. E. F. 1968. Ecology and resource management. McGraw-Hill Book Company, New York. 450 p.

Williams, O. B. 1969. An improved technique for identification of plant fragments in herbivore feces. J. Range Manage. 22:51-52.

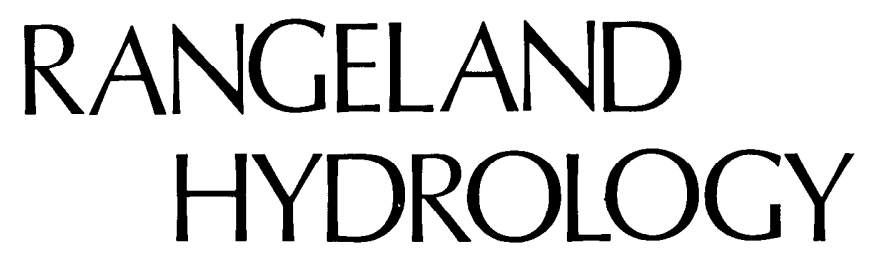

Farrel A. Branson, Geological Survey, USDI

Gerald F. Gifford, Utah State University J. Robert Owen, Geological Survey, USDI

Here is a publication, the first in the Society's RANGE SCIENCE SERIES, that presents a brief but comprehensive summary review of the principles and problems of watershed management on rangelands.

Rangeland Hydrology is an ideal aid for classroom instruction, ${ }^{*}$ as well as an excellent reference for ranchers, research scientists, field workers, and administrators-especially so if one is not quite up-to-date in this particular aspect of range management.

With 72 pages of illustrated text and 234 selected references, this booklet succinctly tells about the relationships between rangeland vegetation and precipitation, interception, runoff, infiltration, erosion and sedimentation, geomorphology, and evaporation/transpiration.

viii +84 p. Illus. $\$ 1.75$ per copy, postpaid.

Order from Society for Range Management, 2120 South Birch Street, Denver, Colorado 80222.

*Special bulk order prices available to college or university departments or bookstores. Write to above address for information. 